\title{
Net primary production of Chinese fir plantation ecosystems and its relationship to climate
}

\author{
L. Wang ${ }^{1,2}$, Y. Zhang ${ }^{2}$, F. Berninger ${ }^{2,3}$, and B. Duan ${ }^{2}$ \\ ${ }^{1}$ Chengdu Institute of Biology, Chinese Academy of Sciences, P.O. Box 416, Chengdu 610041, China \\ ${ }^{2}$ Key Laboratory of Mountain Surface Processes and Ecological Regulation, Institute of Mountain Hazards and Environment, \\ Chinese Academy of Sciences, Chengdu 610041, China \\ ${ }^{3}$ Department of Forest Sciences, P.O. Box 27, 00014, University of Helsinki, Finland
}

Correspondence to: B. Duan (duanbl@imde.ac.cn)

Received: 10 March 2014 - Published in Biogeosciences Discuss.: 14 April 2014

Revised: 30 July 2014 - Accepted: 2 September 2014 - Published: 14 October 2014

\begin{abstract}
This article investigates the relationship between net primary production (NPP) of Chinese fir, temperature and precipitation. The spatial-temporal NPP pattern in the potential distribution area of Chinese fir from 2000-2010 was estimated utilizing a MODIS MOD17 product in a geographic information system (GIS) environment. The results showed that the highest NPP value of Chinese fir is in the Fujian province in the eastern part of the study region. The relationship between NPP of Chinese fir and climate variables was analyzed spatially and temporally. On the regional scale, precipitation showed higher correlation coefficients with NPP than did temperature. The spatial variability pattern indicated that temperature was more important in central and eastern regions (e.g. Hunan and Fujian province), while precipitation was crucial in the northern part (e.g. Anhui province). Zonal analysis revealed that the impact of precipitation on the production was more complicate than that of temperature; larger amount of precipitation is not always corresponding with greater NPP value. When compared to natural forests, plantations appear to be more sensitive to the variability of precipitation, which indicates their higher vulnerability under climate change. Temporally, NPP values decreased despite of increasing temperatures, and the decrease was larger in plantations than among other vegetation types.
\end{abstract}

\section{Introduction}

Chinese fir (Cunninghamia lanceolata (Lamb) Hook), a typical subtropical coniferous tree species, is one of the most important timber species in Southern China due to its fast growth, high yield and excellent wood quality (Wu, 1984). Traditionally, Chinese fir plantations were established after native evergreen broad-leaved forests were harvested, slashed, and burned. Since the 1950s, with the increasing demand for timber because of the economic development, the plantation area of Chinese fir has been enlarged, and the species has been repeatedly planted on the same sites without periods of fallow. Subsequently, decreasing production of Chinese fir plantations has been reported since the 1980s (Fang, 1987; Ma, 2001), primarily due to soil degradation (Ding et al., 1999; Yang et al., 2000). Climate influences the structure and function of forest ecosystems and plays an essential role in the growth and health of forest. Existing studies on the relationship between the productivity of plantations and climate are scarce and limited to plot scale (Chen et al., 1980a, b; Lu, 1980). However, it is necessary to clarify such relationships spatially at the regional level in order to extensively and comprehensively understand the influence of climate on the productivity of plantations. Moreover, climate change affects the growth and production of forests directly through changes in the meteorological drivers of growth and through carbon dioxide fertilization, and indirectly through complex interactions present in forest ecosystems. Temporal analyses of such relationships are indispensable. 
Forest ecosystems have the strongest carbon absorption capacities among all ecosystems. In China, plantations are a significant part of forest ecosystems, and they are very important when studying the carbon budget of terrestrial ecosystems. Since the early 1970 s, the plantation area of China has been gradually increasing to be now the highest in the world. Forests in southern China are primarily plantations, which compose $54.3 \%$ of the total plantation area of China. Carbon uptake by plantations is the most important reason for the increased carbon storage in China (Fang et al., 2001). It contributes about $65 \%$ of the $\mathrm{C}$ sink in the terrestrial ecosystems of southern China (Wang et al., 2009). Zhao and Running (2010) showed that the past decade (2000-2009) was the worldwide warmest one since instrumental measurements of temperatures began in the 1880s. A better understanding of the decadal-scale carbon balance dynamics of plantation ecosystems can benefit the interpretation of observed variation in atmosphere-biosphere carbon exchanges (Fung et al., 1997) and evaluation policies to mitigate anthropogenic $\mathrm{CO}_{2}$ emissions (IGBP Terrestrial Carbon Working Group, 1998).

Net primary production (NPP) has received much attention not only because it is related to the global carbon cycle but also because it is greatly influenced by the changing climate (Prentice et al., 2001). On the regional or global scale, NPP can be estimated by process-based ecosystem models, which are based on the fundamental mechanisms controlling NPP, such as moisture, temperature, solar radiation and nutrition (Running and Coughlan, 1988; Melillo et al., 1993). However, these ecosystem models generally estimate potential NPP, primarily because of the difficulty in obtaining existing and detailed land cover and soil information. On the other hand, satellite remote sensing data can provide nearreal time information regarding vegetation cover, biome type and disturbances (Wang et al., 2013). As a result, models using satellite data make NPP estimation simpler and possibly more accurate (Potter et al., 2004; Ruimy et al., 1994; Field et al., 1995; Zhao et al., 2006).

Remote sensing has been used to monitor gross primary production (GPP) and NPP dynamics on the regional and global scale (Nemani et al., 2003; Zhao et al., 2006). The Moderate Resolution Imaging Spectroradiometer (MODIS) on NASA's satellites, Terra and Aqua, is one of the most reliable data sources to monitor the terrestrial biosphere. The algorithm of MODIS NPP is based on "radiation use efficiency", original logic proposed by Monteith (1972) suggesting that NPP of sufficiently watered and fertilized annual crops is linearly related to the amount of solar energy absorbed by the plants over a growing season. The resulting MODIS GPP and NPP products have been validated as being able to capture spatial and temporal GPP and NPP patterns across various biomes and climate regimes, and they are consistent with the ground flux tower-based GPP and fieldobserved NPP estimation (Zhao et al., 2005). The availability of GPP and NPP calculated from the MODIS data provides a unique opportunity for examining the spatial patterns of NPP in the plantation ecosystem of Chinese fir in southern China and its relationships to climate. Consequently, the objectives of the current study were to (1) explore spatial-temporal patterns of NPP in the potential distribution area of Chinese fir plantations, and (2) to examine the influence of temperature and precipitation on the production of Chinese fir.

\section{Methods}

\subsection{Site description}

The study region chosen for this work is defined by the potential distribution area of Chinese fir plantations, which spans a latitude range from 21.22 to $33.78^{\circ} \mathrm{N}$ and longitude from 97.33 to $121.28^{\circ} \mathrm{E}$ (Wu, 1984). It covers 10 provinces in southern China, including Zhejiang, Fujian, Jiangxi, Hunan, Anhui, Guangdong, Guangxi, Yunnan, Sichuan and Chongqing, with a total area of 134 million hectares (Fig. 1).

The potential distribution area of Chinese fir plantations is in the humid subtropical area in southern China. This is a region of low mountains and hills with a very broken topography and complicated geology. Plantations are generally located on slopes with steepness of more than $20 \%$, gentler lower slopes generally being used for agriculture. The soil type is usually red earth, but the soil can be originated from very different parent materials. The soil conditions vary significantly in terms of texture, depth, fertility, and other physical and chemical characteristics. Naturally, Chinese fir is a component of mixed subtropical evergreen broad-leaved forests $(\mathrm{Wu}, 1984)$.

\subsection{Data collection and processing}

Data sources required in the current study comprised MODIS NPP and GPP data, and land cover and climate data. Remote sensing and geographic information system techniques were employed for processing, analyzing and mapping of all spatial data. In addition, $\mathrm{R}$ programming language ( $\mathrm{R}$ Core Team, 2014), and a suite of $\mathrm{R}$ packages (sp, Bivand et al., 2013; rgdal, Bivand et al., 2014; ggplot2, Wickham, 2009) was utilized for MODIS data download and statistical analysis.

\subsubsection{MODIS data}

MODIS product MOD 17 was chosen for evaluation of GPP and NPP in our study. MODIS data are formatted as a HDF EOS (Hierarchical Data Format - Earth Observing System) tile in a sinusoidal projection with a grid of $1 \mathrm{~km} \times 1 \mathrm{~km}$. Each tile is $1200, \times 1200 \mathrm{~km}$ (Zhao et al., 2005). To cover the study area, six tiles with horizontal numbers from 26 to 28 and vertical numbers from 5-6 for 11 years (2000-2010) were downloaded using the $\mathrm{R}$ script of ModisDownload.R (http://r-gis.net/?q=ModisDownload). Six tiles of each time 


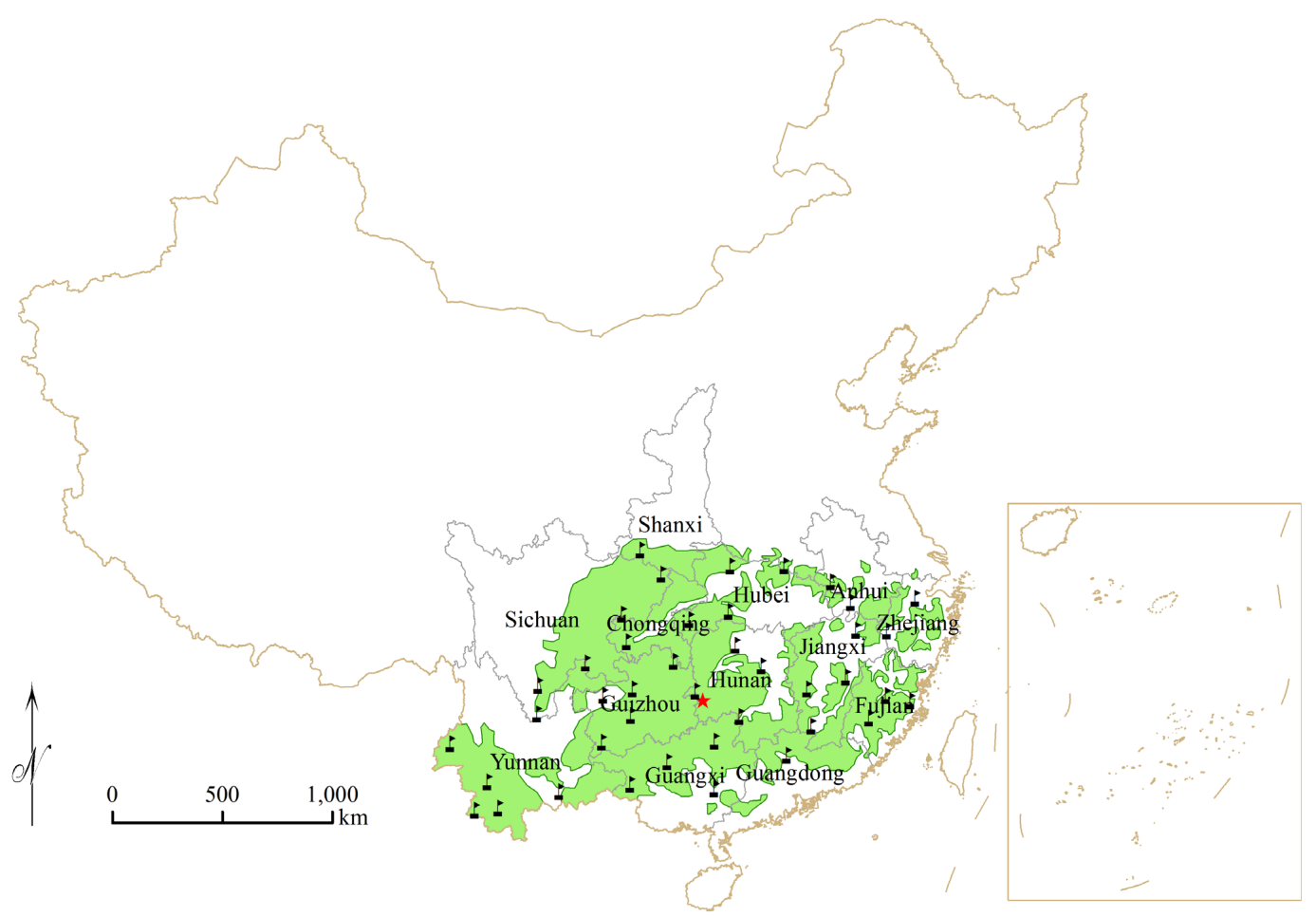

Figure 1. Location of the study area (green) in southern China. Names and borders of provinces are shown. Flags represent weather stations located within the study region. Red asterisk indicates Huitong county, which is the central place of Chinese fir production.

were merged and converted into one GeoTIFF format image using the MODIS Reprojection Tool (MRT). The Sinusoidal projection of each image was transformed into an Albers equal-area projection in the process of converting HDF files into tiff images. The mosaic images were then clipped into the study area in ESRI ArcInfo.

\subsubsection{Land cover data}

The 1-km resolution Landcover 2000 (GLC2000) data consistent geographically with the study area was retrieved from the Global Landcover 2000 web site (Bartholomé and Belward, 2005). The GLC2000 data was based on the SPOT4 vegetation VEGA2000 data set, which provides accurate baseline land cover information. Additionally, the distribution of Chinese fir was specially modified from the artificial Chinese forest map, which we applied from "Data Sharing Network Infrastructure of Earth System Science" (http://www.geodata.cn/), a Chinese web that provides data related to nature science. The distribution area of Chinese fir is corresponding to that of coniferous forest partly in Global Landcover 2000. So we replaced those coniferous forest areas with Chinese fir utilizing ArcGIS software to make a new land cover map that contains Chinese fir. The land cover data was then transformed to the same projection with the MODIS data (Fig. 2).

\subsubsection{Climate data}

Average annual precipitation and temperature data (20002010) from 75 stations were acquired as a text file from Chinese meteorological data sharing service system (http: //cdc.cma.gov.cn). The temperature and precipitation data were transformed into the grid format from the text format in ArcInfo. To match MODIS data and land cover data, ordinary kriging was chosen as an estimator to interpolate the climatic data to be gridded surface with resolution of $1 \mathrm{~km}$ using a module of the geostatistical analyst in ArcGIS. A unified projection corresponding to all other data was then defined for the interpolated temperature and precipitation data. The trends of regional climatic variables in time series were analyzed based on the Mann-Kendall method using R. The Mann-Kendall method is considered to be more suitable for non-normally distributed data, which are frequently encountered in hydro-meteorological time series (Yue et al., 2002).

\subsection{Analysis of NPP temporal change pattern}

The temporal fluxes of NPP over the 11 years of study were examined with the temporal change tendency analysis for 


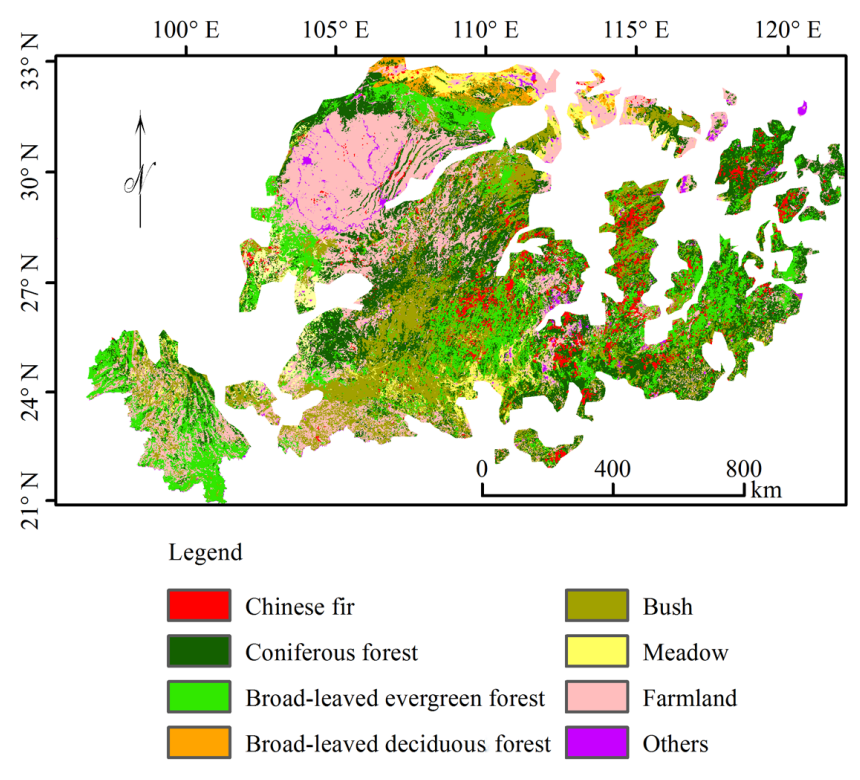

Figure 2. Distribution of eight vegetation classes as retrieved from the Global Landcover 2000 web site and Chinese artificial forest map.

each pixel separately, utilizing the following equation:

$$
Q_{\text {slope }}=\frac{n \times \sum_{i=1}^{n} i \times \mathrm{NPP}_{i}-\left(\sum_{i=1}^{n} i\right)\left(\sum_{i=1}^{n} \mathrm{NPP}_{i}\right)}{n \times \sum_{i=1}^{n} i^{2}-\left(\sum_{i=1}^{n} i\right)^{2}}
$$

where $n$ is the total number of study years and $\mathrm{NPP}_{i}$ is annual NPP during the year $i$ of each pixel (Stow et al., 2003). Positive $Q_{\text {slope }}$ signifies an increasing tendency through the time series, while a negative one infers a decline. A higher absolute value of $Q_{\text {slope }}$ denotes a stronger magnitude of an increase or a decrease. The $Q_{\text {slope }}$ parameter here was used as a binary indicator to show whether NPP is increasing or decreasing at each pixel. Percentages of pixels that decrease growth are presented in the results. Spatially, NPP patterns were characterized by calculating the 11-year average NPP values geographically.

\subsection{Analysis between NPP pattern and climate variables}

To examine the relationship between the geographical NPP pattern and climatic factors, a spatial correlation analysis between the 11-year average NPP and corresponding climate variables was implemented on both regional and pixel scales. The Pearson product moment correlation coefficient $(R)$ was used to calculate the correlation between the NPP and annual mean precipitation and annual mean temperature. A high $R$ value signifies a positive relationship while a low $R$ value represents the opposite. A positive R implies that the NPP has the same trend with temperature or precipitation, while a negative $\mathrm{R}$ implies the opposite. Additionally, a zonal analysis was conducted to examine the NPP pattern along precipitation and temperature gradients. Zonal analysis is one of the most important spatial analysis tools in ArcGIS. It is the creation of an output raster (or statistics table) in which the desired function is computed on the cell values from the input value raster that intersect or fall within each zone of a specified input zone data set (ESRI). The mean NPP value (dependent factor) for each range of precipitation and temperature (independent factors) was calculated using [Zonalstats] of ArcInfo, where the independent factors were used as zones and the dependent factor was used as a value.

\subsection{Validation of MODIS data using flux tower data}

Eddy flux towers provide valuable opportunities to validate satellite data, because they measure carbon, water and energy exchange on a long-term and continuous basis (Running et al., 1999). GPP derived from eddy flux measurements in Qianyanzhou, Jiangxi province, was employed to validate MODIS GPP. Vegetation around the tower is mainly artificial forest with the stand age around 30 years including, e.g. planted pine and Chinese fir (Ma et al., 2010). Eddy flux GPP on daily basis in 2006 were provided by Qianyanzhou Experimental Station. Correspondingly, MODIS GPP data in 2006 were downloaded. To match the footprint, subsets of $4 \times 4$ pixels around the tower were extracted. In accordance with MODIS GPP, which is an 8-day composite, 8-day summations of eddy flux GPP were created to make a correlation with average of MODIS GPP subsets.

\section{Results}

\subsection{Characteristics of climate variables}

Spatially, hydrothermal gradients present zonal characteristics. It is evident that temperatures in the south and east are higher than those in the north and west (Fig. 3a, b). On the other hand, precipitation featured a decreasing trend from southeast to northwest. The mean decadal temperature gradually increased from 2000-2010 based on the MannKendall analysis (Fig. 3c), which was in an agreement with the overall warming trend. Moreover, the annual precipitation slightly decreased following a linear trend over the study years (Fig. 3d).

\subsection{Spatial-temporal pattern of NPP}

GPP from Eddy flux measurements in Qianyanzhou was used to validate MODIS GPP (Fig. 4). The result showed a good correlation between the two data sources $(r=0.79$, $P<0.0001)$. Vegetation production in the current study was characterized utilizing NPP value intervals, which presented great spatial variability (Fig. 5a). For the entire study area, 

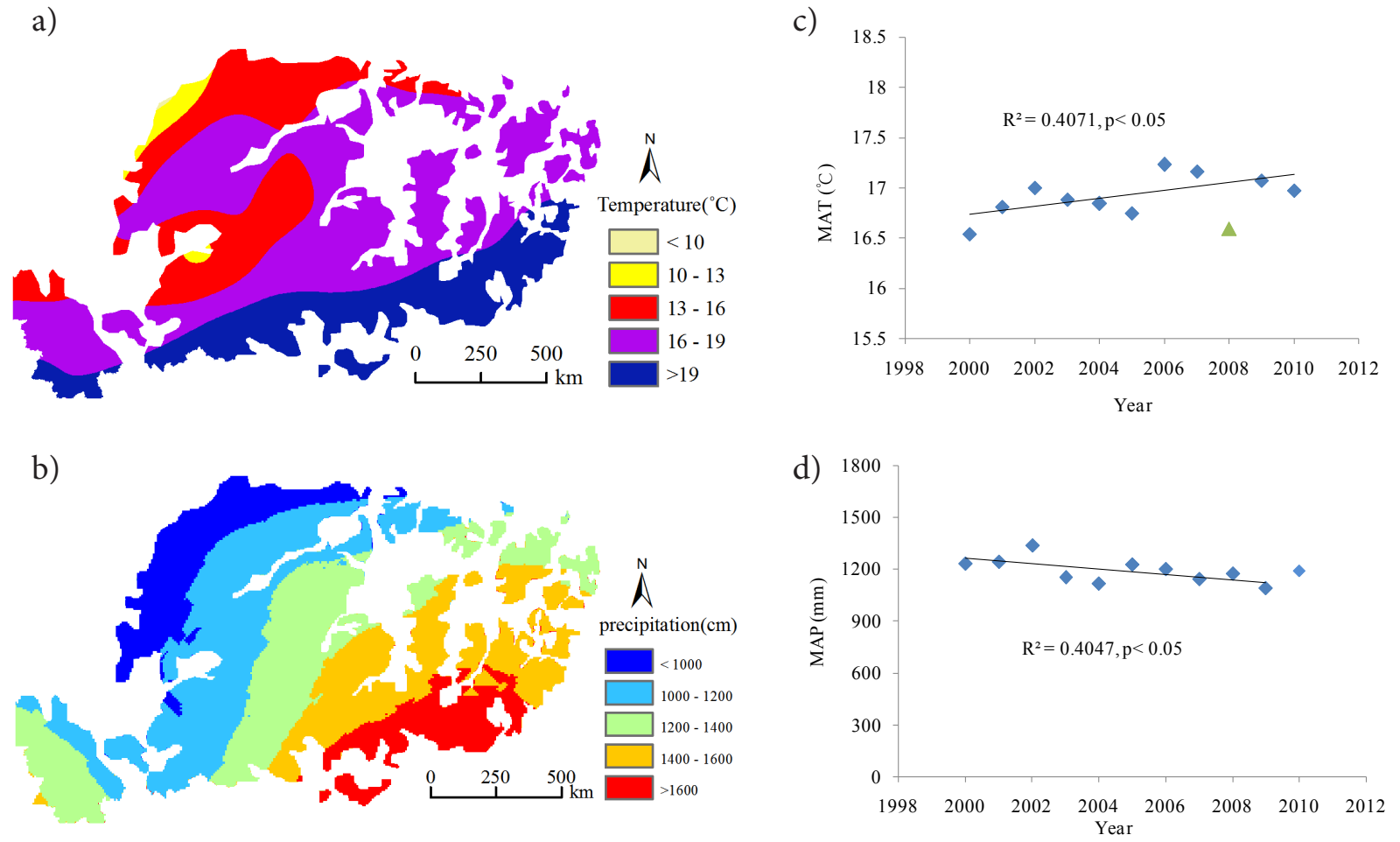

Figure 3. Spatial patterns and temporal changes of climate variables in the study region. (a) temperature surface; (b) precipitation surface; (c) mean annual temperature (MAT); (d) mean annual precipitation (MAP). Mean annual temperature shows significantly increasing trend except a relatively low value in 2008, while mean annual precipitation shows significantly decreasing trend during the study years.

the average production in the south and east is higher than that in the north and west. The area with the highest production was located in the southern part of the Yunnan province, where the dominant vegetation is composed of a broad-leaved evergreen forest. NPP of the broad-leaved evergreen forest in the Fujian province is the second highest within the whole study region. The third highest NPP was in the southeastern part of the Sichuan province. The broadleaved evergreen forests in the middle and northern parts of the study area presented relative low NPP values. Among conifer forests, the highest values were found in the southern part of the study region, followed by most of the Fujian province, the western region and some regions of the $\mathrm{Hu}-$ nan and Jiangxi provinces. The lowest NPP values of conifer forests are present in the northern part of the study region. In particular, as a type of a conifer forest, Chinese fir exhibits a similar NPP pattern as coniferous forests in general, except that it has its highest NPP value in the Fujian province in the eastern part of the study region, but lower values in the southern, western, central and northern part of the study region. In general, in the potential distribution area of Chinese fir plantations, broad-leaved evergreen forests have the highest production (Fig. 5b). Compared to NPP of other coniferous forests in the region, the value of Chinese fir is relatively low, $626 \mathrm{~g} \mathrm{C} \mathrm{m}^{-2} \mathrm{yr}^{-1}$.
Temporally, from 2000-2010, the NPP values of Chinese fir showed a decreasing trend (Fig. 6). During the period of 11 years, the highest NPP occurred in 2002 and the lowest one in 2009. The difference between these 2 years was $100 \mathrm{~g}$ $\mathrm{C}$, about $15 \%$ of the average NPP.

The results of the spatial-temporal changes of NPP were obtained from the temporal change tendency analysis conducted for the study years (Fig. 7a). The results showed a great increase in NPP in the Fujian province and in the northern part of the study region. Parts of Sichuan, Guizhou and Yunnan provinces, areas near the margins of the study region, also had similar tendencies. On the contrary, NPP in most regions of Hunan and Jiangxi provinces declined over the study period. Overall, the main production area of Chinese fir had an evidently decreasing productivity, while NPP around most of the margin area increased. In terms of vegetation type, percentages of NPP decreases during the period of 11 years are presented in Fig. 7b. Farmland and deciduous broad-leaved forest showed mostly increasing NPP values during the study years, while coniferous and evergreen broad-leaved forests had areas with both increasing and decreasing NPP, with the proportions of decreasing NPP equaling 50 and $55 \%$, respectively. Chinese fir showed the especially high NPP decrease of $66 \%$. 


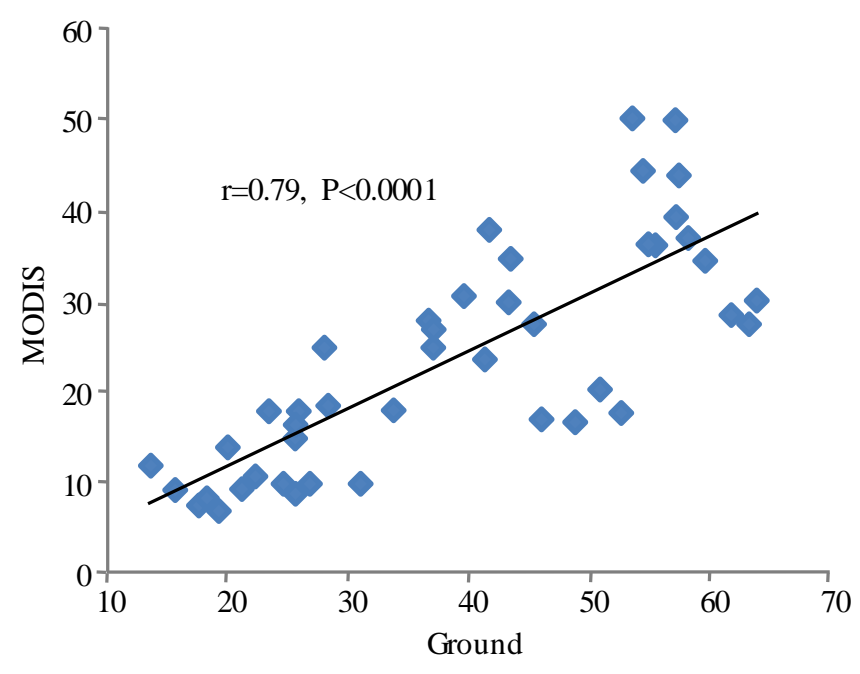

Figure 4. A linear comparison of MODIS GPP and observed gross primary production $\left(\mathrm{g} \mathrm{C} \mathrm{m}^{-2} \times \mathrm{d}^{-1}\right)$ at the eddy flux tower site in Qianyanzhou, Jiangxi province. MODIS data are positively related to ground data $(r=0.79, P<0.0001, n=25)$.

\subsection{Relationship between NPP pattern and climate variables}

Representations of spatial patterns may be different when observed on different scales. In order to comprehensively clarify the relationship between the NPP pattern and climatic factors, an analysis was conducted at three levels: the entire study region, zonal analysis and pixel scale. Regionally, both temperature and precipitation presented positive correlations with NPP values, where the correlation with precipitation was significant and higher than that for temperature (Fig. 8a, b). The relationship between the NPP pattern and climatic factors was further examined through a correlation analysis between NPP of each pixel and climate geographically corresponding to NPP. The yearly average NPP and corresponding yearly data of climate variables were correlated to each other using the Pearson product moment correlation. Correlation coefficients of NPP and annual mean precipitation are shown in Fig. 9a. High correlations between the two variables were found in the central and northern part of the whole study region, while low or negative correlations were detected in most southern regions. The correlation coefficients between NPP and annual mean temperature are shown in Fig. 9b. The central areas of the study region presented high $r$ values, especially Hunan, Jiangxi and Chongqing provinces, whereas negative $r$ values were found within the southern margin of the study region. For comparison, in the central and eastern areas of Chinese fir, NPP values were more strongly correlated to temperature than to precipitation. In the northern part they exhibited higher correlations with precipitation than with temperature, and in the southern part negative correlations with both temperature and precipitation.
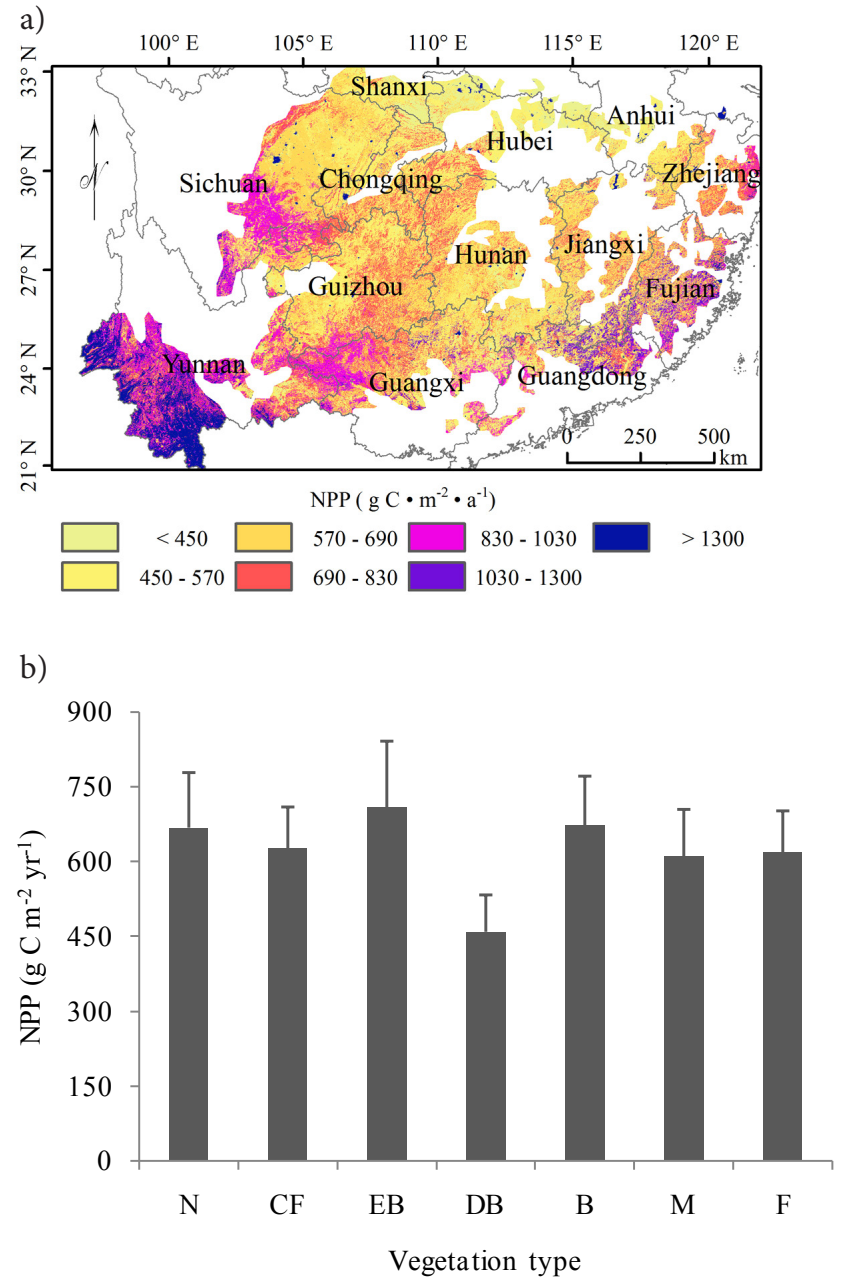

Figure 5. Spatial pattern of NPP in the study region. (a) spatial pattern of average NPP during study years, the intervals was chosen based on the quartile of cumulative distribution of the NPP; (b) the mean NPP of each vegetation type. Error bars represent standard deviation within vegetation type. Abbreviations: N, coniferous forest; $\mathrm{CF}$, Chinese fir; EB, evergreen broad-leaved forest; DB, deciduous broad-leaved forest; B, bush; F, farmland; M, meadow.

Additionally, the analysis of the NPP pattern along each climatic factor was implemented utilizing a zonal analysis. Especially, the NPP patterns of Chinese fir, coniferous forests and broad-leaved forests along climate variables were analyzed and compared. For all three vegetation types, NPP along precipitation exhibited a more complex pattern than along temperature (Fig. 10). In terms of precipitation, the NPP values of Chinese fir present a gradual increase with the precipitation above $1400 \mathrm{~mm}$ and below $1700 \mathrm{~mm}$, with a sharp decrease above $1700 \mathrm{~mm}$, and the same pattern was found in coniferous and broad-leaved forests (Fig. 10a, c, e). Along decreasing precipitation below $1400 \mathrm{~mm}$, the productivity of both coniferous and broad-leaved forests presented a similar pattern: decreasing NPP with precipitation above 


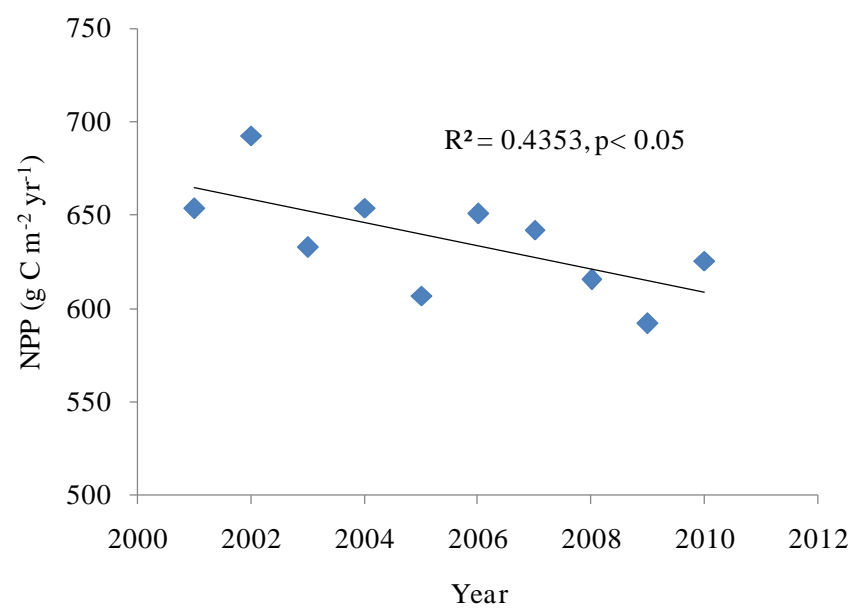

Figure 6. Temporal changes of the total net primary production of Chinese fir in the study region from 2000-2010 exhibit a significant decreasing trend.

$970 \mathrm{~mm}$ and a sudden increase above $1100 \mathrm{~mm}$ and then a gradual decrease until $1400 \mathrm{~mm}$. Such a pattern is not obvious in Chinese fir, except that there is a sudden change at the precipitation level of $1100 \mathrm{~mm}$.

In terms of temperature (Fig. 10b, d, f), an increasing trend of NPP of Chinese fir is evident from the turning point temperature of $15.5^{\circ} \mathrm{C}$, with a short, relatively stable interval ranging from 15.5 to $19^{\circ} \mathrm{C}$. A similar pattern was found in coniferous and broad-leaved forests, with a small difference within the interval from 15.5 to $19^{\circ} \mathrm{C}$. Within this interval, the NPP values of coniferous forests present a gradual increase, while broad-leaved forests exhibit a sudden increase and then a slow decrease. In comparison, the pattern of NPP along the annual average temperature experienced by Chinese fir is similar with that of coniferous forests, both of which experience decreasing NPP values along the temperature until $15.5^{\circ} \mathrm{C}$ despite stronger NPP fluctuation in Chinese fir and a greater decrease in coniferous forests. NPP along temperature presents a more complicated pattern in broadleaved forests. First there is an increase in NPP, followed by a sudden decrease right before the turning point of about $15.5^{\circ} \mathrm{C}$.

\section{Discussion}

\subsection{Spatial pattern of NPP and climatic conditions}

We got a good correlation between MODIS GPP and GPP from eddy flux measurements $(r=0.79, P<0.0001)$ that was similar to the correlation in another study using satellite data from China (Wang et al, 2013). MODIS GPP can be used to estimate the GPP within a pixel (an area of $1 \mathrm{~km}^{2}$ in current study), while eddy tower measures GPP over a footprint that changes according to the wind speed and wind di-
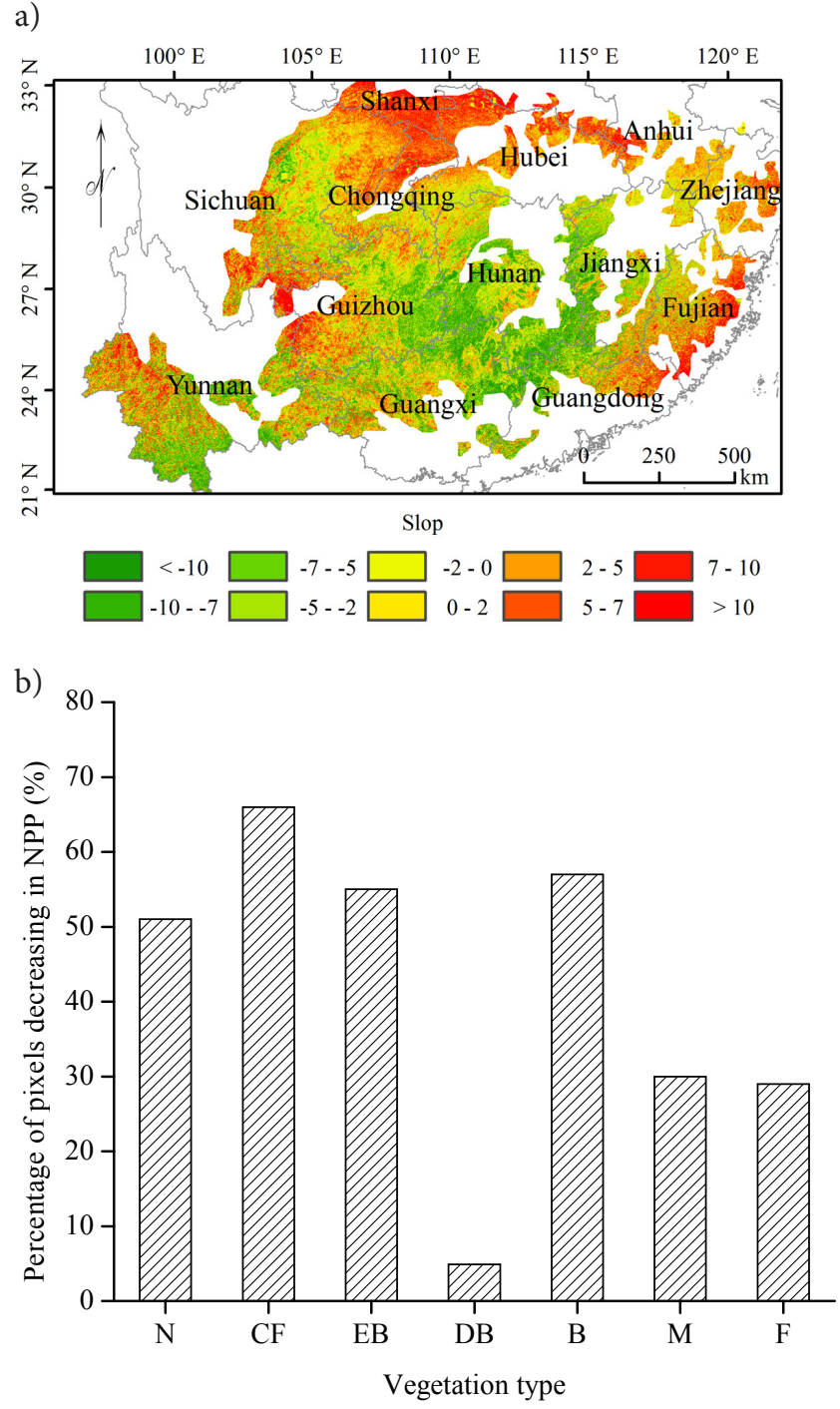

Figure 7. Temporal pattern of NPP in the study region. (a) pixelbased NPP temporal change trend from 2000-2010; (b) the percentage of areas showing a decrease in NPP for each vegetation type. Abbreviations: N, coniferous forest; $\mathrm{CF}$, Chinese fir; EB, evergreen broad-leaved forest; DB, deciduous broad-leaved forest; $\mathrm{B}$, brush; F, farmland; M, meadow.

rection in 1 year. Differences in the spatial scales of the two methods may lead to differences in the predicted GPP of the MODIS-GPP algorithm and eddy tower (Wang et al, 2013).

To characterize the spatial pattern of temperature and precipitation, we chose ordinary kriging as an estimator to interpolate the station data. Ordinary kriging is a linear optimum interpolation method for regionalized single variable with the minimum variance of the estimation variance. A cross-validation was conducted to estimate the interpolation accuracy, which showed a high correlation coefficient of 0.92 between the original temperature data and predicted kriging value, and 0.85 for that of precipitation data. Moreover, 

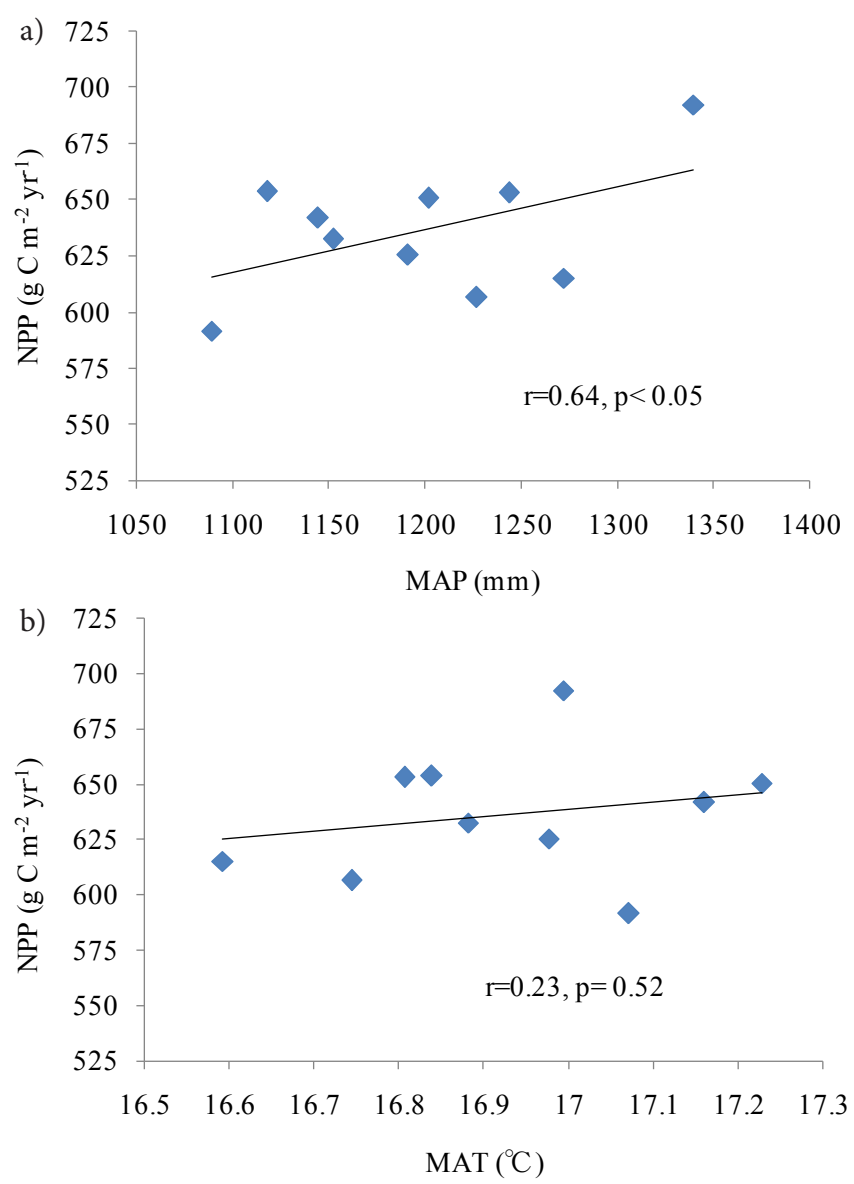

Figure 8. Correlation between net primary production of Chinese fir and climate variables from 2000-2010 on a regional scale. (a) Mean annual precipitation (MAP); (b) mean annual temperature (MAT). They both show linear trends. NPP of Chinese fir is significantly correlated to MAP but not to MAT.

we compared our climatic data with WorldClim data (http: //www.worldclim.org/), which is a set of global climate layers (climate grids) with a spatial resolution of about 1 square kilometer, and found a very similar characteristic between the the two data sets.

Factors in the physical environment that the growth and development of plants are radiation, temperature, water and nutrients (Atkinson and Porter, 1996). Three of these four factors are climatic. Previously, a site analysis between climatic variables and the growth of Chinese fir has been conducted on a local scale (Chen, 1980a). It was concluded that in Hunan and Guizhou provinces, within the central part of the current study area, temperature was most strongly correlated with the growth of Chinese fir, while in the Anhui province, within the northern part of the current study area, the most strongly affecting climate factor was precipitation. These previous results were consistent with our findings based on a correlation analysis on a pixel scale, which char- acterized the relationship between NPP and climate variables in more detail (Fig. 7a).

Generally, forest production is correlated with both precipitation and temperature. Greater precipitation and higher temperatures are accompanied with a higher production, as shown in our results where the production in the south and east was higher than that in the north and west. Del Grosso (2008) pointed that precipitation was better correlated with NPP than temperature. In our study, considering the whole study area, precipitation had a greater correlation with NPP than did temperature on a regional scale (Fig. 8). However, pixel-based correlation analyses between climate variables and NPP showed that the relationship had great spatial variability: NPP values were more strongly correlated with temperature than precipitation in the central and eastern part of the study region, while NPP exhibited a greater correlation with precipitation than with temperature in the northern part (Fig. 9). These results brought out the importance of the scale effect. In the zonal analysis, NPP values generally increased along both increasing precipitation and temperature gradients. However, NPP values along the precipitation gradient presented more variability, which indicated that the effect of precipitation on production is more complicated. Chen et al. (2005) have suggested that the yearly distribution of precipitation has a strong effect on the natural vegetation growth. In the current study, NPP values tended to decrease when precipitation was more than $1700 \mathrm{~mm}$ (Fig. 10a, c, e). High amounts of precipitation occur in the southern region of the study area, such as Guangdong and Guangxi provinces, where rainfall is distributed unevenly (Chen, 1980a), causing periods of ample water supply but also drought. This also explains why the production in the southern part of the study site has a negative correlation with precipitation based on the pixel level analysis. Additionally, plantations appear to be more sensitive to precipitation variability. As the results indicated, Chinese fir has its highest production in the eastern part of the study region, not in the southern part as the natural forest did, which is the only difference in the spatial pattern between artificial and natural forests.

\subsection{Climate change and NPP}

Liu (2010) has conducted an analysis on spatial-temporal changes in the climate of China that the average temperature has increased significantly at the rate of $0.2{ }^{\circ} \mathrm{C}$ per decade over the period of 1955-2000 in south-eastern China (Liu et al., 2010). Additionally, the average growing season has shifted 4.6-5.5 days forward and the average end has been 1.8-3.7 days prolonged, increasing the length of the growing season by 6.9-8.7 days (Liu et al., 2010). For our data, a similar trend of increasing temperatures was recorded for the period (2000-2010). Warming tends to accelerate flowering and prolong the photosynthetically active period (Cleland et al., 2006; Berninger, 1997). Moreover, the length of the growing season influences the annual vegetation production, 
a)

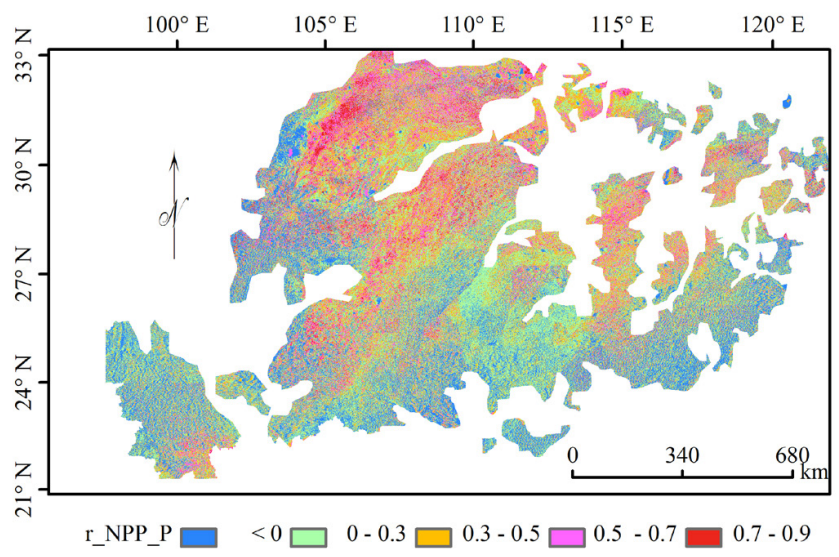

b)

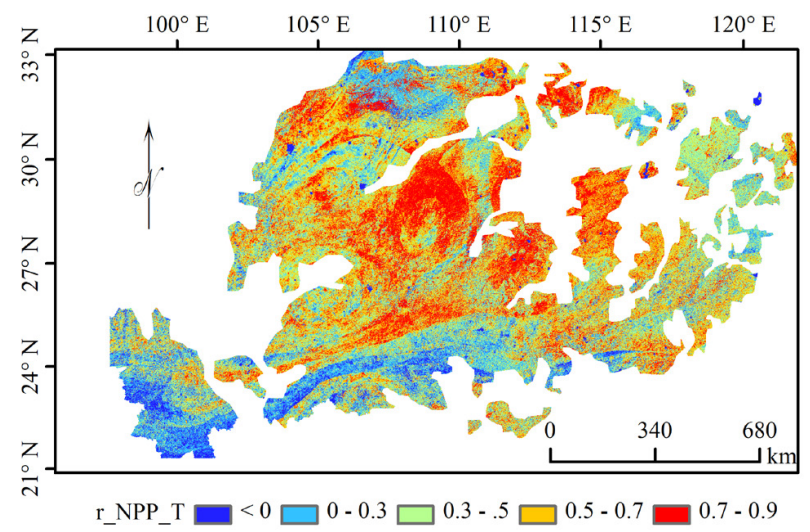

Figure 9. Pixel scale correlation coefficients between NPP and (a) annual mean precipitation and; (b) annual mean temperature.

longer seasons favoring the accumulation of organic matter. Consequently, the production of vegetation will probably increase along an increasing temperature. However, in the current study, the analysis on the temporal tendencies of NPP indicated variability among different vegetation types, of which only farmland and deciduous broad-leaved forest showed an increase over most regions of the study area during the period of 11 years. NPP values of Chinese fir decreased for most pixels in most areas of the study region, especially in the central production areas of Hunan and Jiangxi provinces. Unlike in natural forests, the growth of plantation forests is manipulated by human beings to some extent. Opposite to crops, the NPP values of plantations showed the largest decreases among all vegetation types. There are two possibilities accounting for such phenomenon. One possible reason is man-made causes, such as land use change or inappropriate silvicultural management which results in soil degradation that influences the growth of plantations (Ding et al., 1999; Yang et al., 2000). Fires, harvest, deforestation or other disturbances that change the land-use could alter terrestrial net fluxes at regional and global scales. However, it is extremely challenging to estimate the carbon balance change associated with land-use change because of current lack of information on the amount and spatial pattern of deforestation (Piao et al., 2012; Houghton, 2007). However, most of the plantation in southern China is owned by a collective. Farmers has always been repeatedly planting Chinese fir on the same sites without intercropping or periods of fallow (Bi et al., 2007), which reduce the land-use change impact. The other reason could be changing climate. Trees have a higher maintenance cost. Kremer et al. (1996) proposed that a high air temperature also increases the maintenance respiration, leading to decreases in NPP. In this study, broad-leaved and broad-leaved deciduous forests were found to exhibit different changes during the study years. NPP of broad-leaved forests decreased considerably, while decidu- ous forests showed a strong increase. Such a difference indicated that the maintenance respiration of broad-leaved forests in winter has probably greatly increased due to warming temperature.

It is evident that the production of vegetation in the study region did not benefit from an increasing temperature. Despite the potential effects of increasing maintenance respiration or anthropogenic influence, factors related to climate change, for instance increasing variability in rainfall, enhanced frequency of extreme weather events, such as cold waves, droughts and floods (Solomon et al., 2007), can influence the production of vegetation. The central and southern parts of our study region experienced several extreme weather events during the study years, including droughts in autumn 2004, floods and hurricanes in 2007 and snowstorms in 2008. Our results (Fig. 6) show that NPP of Chinese fir decreased in 2005 , which was to some extend influenced by autumn droughts in 2004. Floods and hurricanes in 2007 also corresponded with a declined NPP value in 2007 compared to that in 2006. While snowstorms in 2008 made the NPP value even lower than that in 2007 . These events could potentially increase the variability in precipitation, which may further explain why the production of plantations had the greatest decreases, if they were more sensitive than natural forests to precipitation variability. Additionally, as the climate changes, extreme events are becoming more frequent on average (Solomon et al., 2007), which would potentially influence plantation production, as relatively simple plantation ecosystems are highly vulnerable (Hartley, 2002). Consequently, the capacity of carbon sequestration by artificial plantations would be threatened. However, since the forest area in China has been increasing strongly (Piao et al., 2012), growth stocks of Chinese forests are still increasing. 
a)

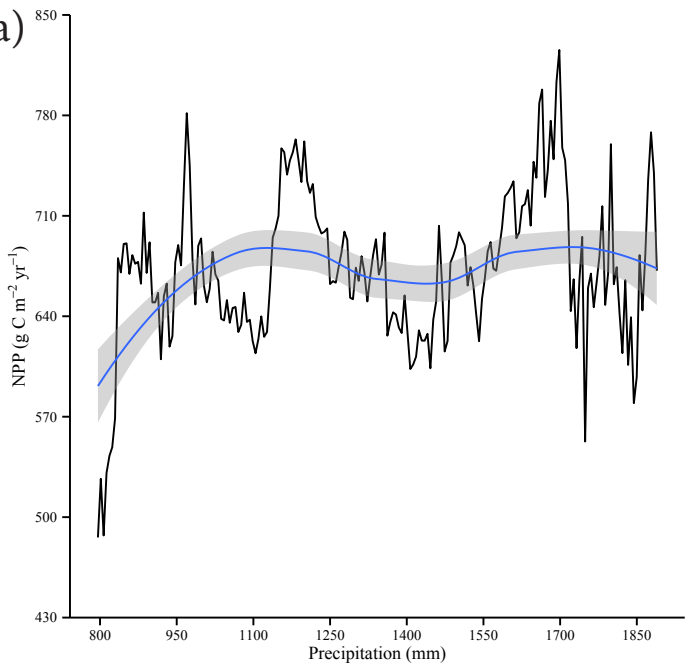

c)

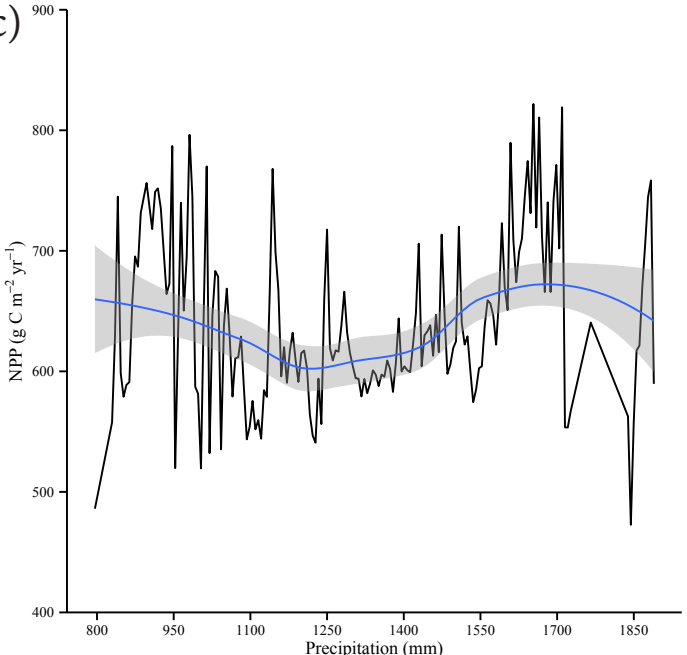

e)

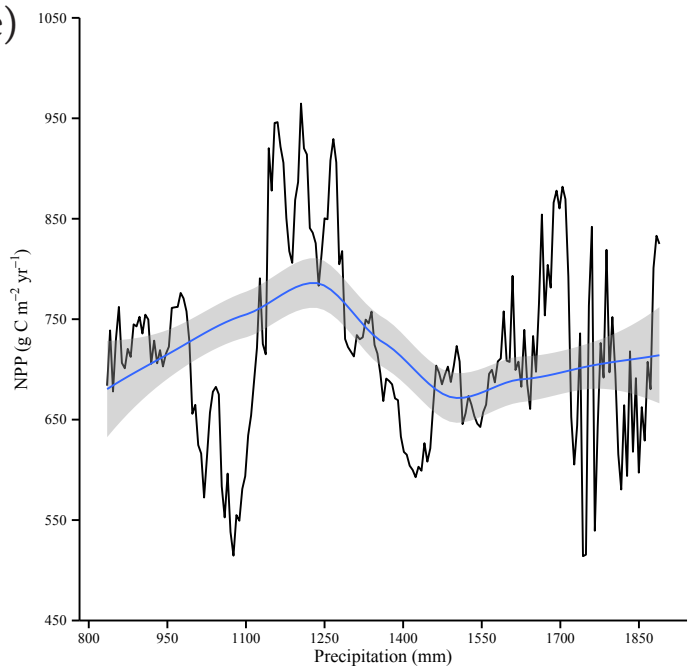

b)

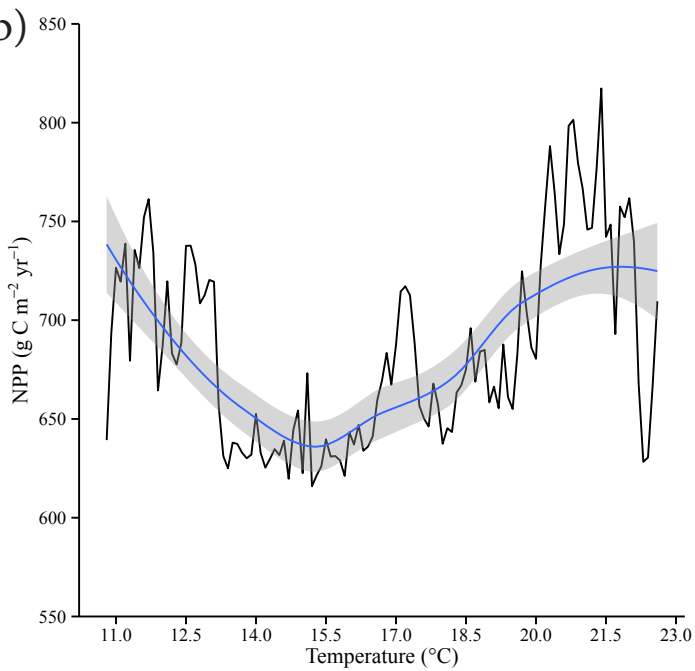

d)

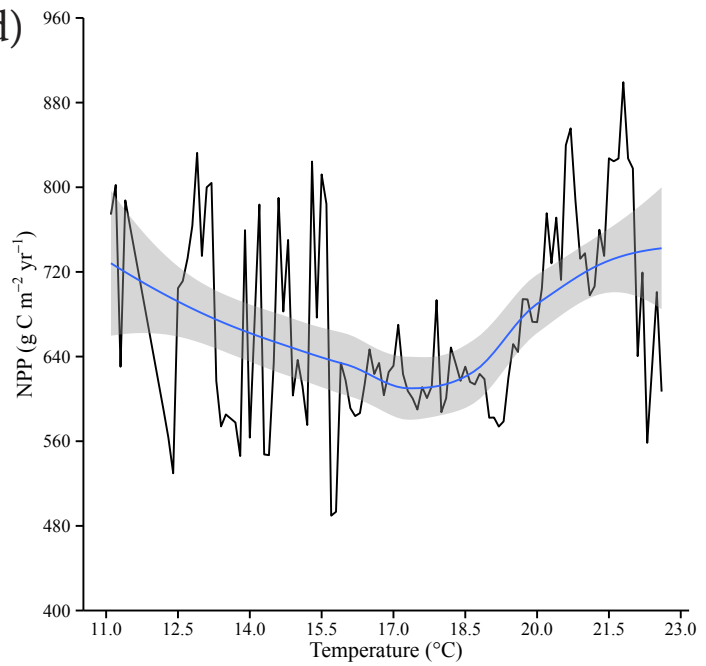

f)

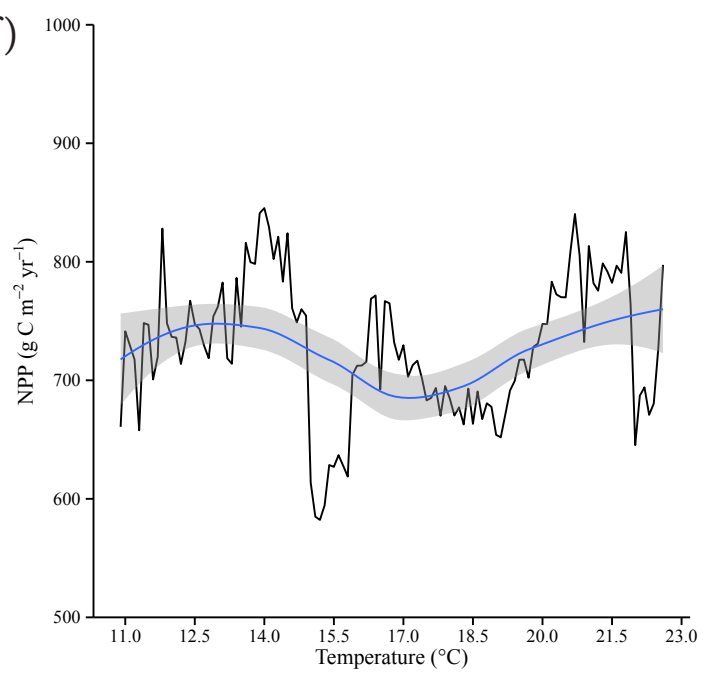

Figure 10. Zonal analysis of the NPP pattern of (a) coniferous forest with precipitation; (b) coniferous forest with temperature; (c) Chinese fir with precipitation; (d) Chinese fir with temperature; (e) broad-leaved forest with precipitation; (f) broad-leaved forest with temperature. Thin lines connect points representing the average NPP against precipitation or temperature. Bold lines represent conditional averages. 


\section{Conclusions}

The current study aimed to characterize the spatial-temporal pattern of NPP and reveal how it is related to climatic factors in the potential distribution area of Chinese fir. A series of spatial analyses were implemented to characterize the spatial pattern of NPP and climate factors, and to analyze the impact of those factors on NPP. Generally, the production of vegetation increased with the increasing precipitation and temperature, presenting a consistent spatial pattern. Both broad-leaved forests and natural coniferous forests had their overall highest production in the southern region, where the mean precipitation is highest although most variable. On the other hand, Chinese fir showed its highest NPP in the eastern region, which revealed that it is more vulnerable to precipitation variability than natural forests. Consequently, the increased frequency of extreme weather events occurring in southern China, potentially resulting from global climate change, might influence the growth of tree plantations. The results of the current study showing that NPP of Chinese fir decreased more than that of other vegetation types during the study years could be a consequence of the climate change. Thus, carbon sequestration of artificial plantations could be a matter of concern. These findings are expected to assist when developing strategies for the sustainable development of Chinese fir plantations.

Acknowledgements. The research was supported by the National Key Basic Research Program of China (no. 2012CB416901), Young Talent Team Program of the Institute of Mountain Hazards and Environment (SDSQB-2012-01) and Chinese Academy of Sciences Visiting Professorships for Senior International Scientists (2013T1Z0028). We are grateful to the researchers in Qianyanzhou Experimental Station for providing the flux tower GPP data.

Edited by: S. Fontaine

\section{References}

Atkinson, D. and Porter, J.: Temperature, plant development and crop yields, Trends Plant Sci., 1, 119-124, 1996.

Bartholomé, E. and Belward, A.: a new approach to global land cover mapping from Earth observation data, Inter. J. Remote Sens., 26, 1959-1977, 2005.

Berninger, F.: Effects of drought and phenology on GPP in $\mathrm{Pi}$ nus sylvestris: a simulation study along a geographical gradient, Funct. Ecol., 11, 33-42, 1997.

Bi, J., Blanco, J. A., Seely, B., Kimmins, J. P., Ding, Y., and Welham, C.: Yield decline in Chinese-fir plantations: a simulation investigation with implications for model complexity, Can. J. For. Res., 37, 9, 1615-1630, 2007.

Bivand, R., Pebesma, E., and Gomez-Rubio Z.: Applied spatial data analysis with R, Second edition, Springer, NY, 2013.

Bivand, R., Tim, K., and Barry, R.: "rgdal: Bindings for the Geospatial Data Abstraction Library”, R package version 0.8-16, 2014.
Chen, C., Feng, Z., and Dong, M.: Correlative analysis between the growth of Cunninghamia lanceolata and climate factors. Ecological Studies on the Artificial Cunninghamia lanceolata Forests (Chinese), 65-86, 1980a.

Chen, C. and Feng, Z.: Studies on the microclimate of the artificial Cunninghamia lanceolata forests in Hui-Tong county of $\mathrm{Hu}-$ nan province, Ecological Studies on the Artificial Cunninghamia lanceolata Forests (Chinese), 87-97, 1980b.

Chen, Z., Wang, S., Wang, Y., and Zhao, B.: Degradation of Inner Mongolia grassland ecosystem and management through fencing and ecological migrating, The Japan-Korea-China Symposium on Grassland Agriculture and Animal Production, 27-29, 2005.

Cleland, E., Chiariello, N., Loarie, S., Mooney, H., and Field, C.: Diverse responses of phenology to global changes in a grassland ecosystem, PNAS, 103, 13740-13744, 2006.

Del Grosso, S., Parton, W., Stohlgren, T., Zheng, D., Bachelet, D., Prince, S., Hibbard, K., and Olson, R.: Global potential net primary production predicted from vegetation class, precipitation, and temperature, Ecol., 89, 8, 2117-2126, 2008.

Ding, Y., Tian, Y., and Qi, L.: A testing simulation with forecast on long-term productivity of Chinese-fir plantations, Forest. Stud. China, 1, 34-38, 1999.

Fang, J., Chen, A., Peng, C., Zhao, S., and Ci, L.: Changes in forest biomass carbon storage in China between 1949 and 1998, Science, 292, 2320-2322, 2001.

Fang, Q.: Influence of continuous cropping on soil fertility and stand growth in Chinese-fir plantations, Sci. Silvae Sin., 23, 389397, 1987.

Field, C., Randerson, J., and Malmstrom, C.: Global net primary production: combining ecology and remote sensing, Remote Sen Environ., 51, 74-88, 1995.

Fung, I., Field, C., Berry, J., Thompson, M., Randerson, J., Malmström, C., Vitousek, P., Collatz, G., Sellers, P., Randall, D., Denning, A., Badeck, F. ,and John, J.: Carbon 13 exchanges between the atmosphere and biosphere, Global Biogeochem. Cy., 11, 507-533, 1997.

Hartley, M.: Rationale and methods for conserving biodiversity in plantation forests, For. Ecol. Manage, 155, 81-95, 2002.

Houghton, R.: Balancing the global carbon budget, Annu. Rev. Earth Planet. Sci., 35, 313-347, 2007.

IGBP Terrestrial Carbon Working Group,: The terrestrial carbon cycle: implications for the Kyoto Protocol, Science, 280, 13931394, 1998.

Kremer, R., Hunt, E., Running, S., and Coughlan, J.: Simulating vegetational and hydrologic responses to natural climatic variation and GCM-predicted climate change in a semi-arid ecosystem in Washington, USA J. Arid Environ., 33, 23-38, 1996.

Liu, B., Henderson, M., Zhang, Y., and Xu, M.: Spatiotemporal change in China's climatic growing season: 1955-2000, Clim. Change, 99, 93-118, 2010.

Lu, H.: A discussion on wood structure of Cunninghamia lanceolata for different age stages and relation between false ring and climatic factors, Ecological Studies on the Artificial Cunninghamia lanceolata Forests (Chinese), 226-237, 1980.

Ma, X.: Advance in researches on productivity decline of replanting Chinese-fir forests, J. Fujian For. Coll., 21, 380-384, 2001.

Ma, Z., Wang, H., Wang, S., Li, Q., Wang, Y., and Wang, H.: Impact of a severe ice storm on subtropical plantations at Qianyanzhou, Jiangxi, China, Chin. J. Plant Ecol., 34, 204-212, 2010. 
Melillo, J., McGuire, A., Kicklighter, D., Moore, III B., Vorosmarty, C., and Schloss, A.: Global climate change and terrestrial net primary production, Nature, 363, 234-240, 1993.

Monteith, J.: Solar radiation and productivity in tropical ecosystems, J. Appl. Ecol., 9, 747-766, 1972.

Nemani, R., Keeling, C., Hashimoto, H., Jolly, W., Piper, S., Tucker, C., Myneni, R., and Running, S.: Climate-driven increases in global terrestrial net primary production from 1982 to 1999 , Science, 300, 1560-1563, 2003.

Piao, S. L., Ito, A., Li, S. G., Huang, Y., Ciais, P., Wang, X. H., Peng, S. S., Nan, H. J., Zhao, C., Ahlström, A., Andres, R. J., Chevallier, F., Fang, J. Y., Hartmann, J., Huntingford, C., Jeong, S., Levis, S., Levy, P. E., Li, J. S., Lomas, M. R., Mao, J. F., Mayorga, E., Mohammat, A., Muraoka, H., Peng, C. H., Peylin, P., Poulter, B., Shen, Z. H., Shi, X., Sitch, S., Tao, S., Tian, H. Q., Wu, X. P., Xu, M., Yu, G. R., Viovy, N., Zaehle, S., Zeng, N., and Zhu, B.: The carbon budget of terrestrial ecosystems in East Asia over the last two decades, Biogeosciences, 9, 3571-3586, doi:10.5194/bg-9-3571-2012, 2012.

Potter, C., Klooster, S., Myneni, R., and Genovese, V.: Terrestrial carbon sinks predicted from MODIS satellite data and ecosystem modeling, Earth Observer, 16, 15-20, 2004.

Prentice, I., Farquhar, G., Fasham, M., Goulden, M., Heimann, M., Jaramillo, V., Kheshgi, H., Le Quéré, C., Scholes, R., and Wallace, D.: The carbon cycle and atmospheric carbon dioxide, in Climate Change, Cambridge University Press, New York, 182237, 2001

Prentice, I., Farquhar, G., Fasham, M., Goulden, M., Heimann, M., Jaramillo, V., Kheshgi, H., and R Core Team: "R: A language and environment for statistical computing”, R Foundation for Statistical Computing, Vienna, Austria, 2014.

Ruimy, A., Dedieu, G., and Saugier, B.: Methodology for the estimation of terrestrial net primary production from remotely sensed data, J. Geophys. Res., 99, 5263-5284, 1994.

Running, S. and Coughlan, J.: A general model of forest ecosystem processes for regional applications: I. Hydrologic balance, canopy gas exchange and primary production processes, Ecol. Modell., 42, 125-154, 1988.

Running, S., Baldocchi, D., Turner, D., Gower, S., Bakwin, P., and Hibbard, K.: A global terrestrial monitoring network integrating tower fluxes, flask sampling, ecosystem modeling and EOS satellite data, Remote Sens. Environ., 70, 108-128, 1999.
Solomon, S., Qin, D., Manning, M., Chen, Z., Marquis, M., Averyt, K., Tignor, M., and Miller, H. (eds.): IPCC: Climate Change 2007: The Physical Science Basis. Contribution of Working Group I to the Fourth Assessment Report of the Intergovernmental Panel on Climate Change, Cambridge University Press, Cambridge, United Kingdom and New York, NY, USA, 2007.

Stow, D., Daeschner, S., Hope, A., Douglas, D., Petersen, A., Myneni, R., Zhou, L., and Oechel, W.: Variability of the seasonally integrated normalized difference vegetation index across the north slope of Alaska in the 1990s, Inter. J. Remote Sens., 24, 1111-1117, 2003.

Wang, L., Tian, B., Masoud, A., and Koike, K.: Relationship between remotely sensed vegetation change and fracture zones induced by the 2008 Wenchuan earthquake, China, J. Earth Sci., 24, 282-296, 2013.

Wang, Q., Wang, S., and Zhang, J.: Assessing the effects of vegetation types on carbon storage fifteen years after reforestation on a Chinese fir site, For. Ecol. Manage., 258, 1437-1441, 2009.

Wang, X., Ma, M., Li, X., Song, Y., Tan, J., Huang, G., Zhang, Z., Zhao, T., Feng, J., Ma, Z., Wei, W., and Bai, Y.: Validation of MODIS-GPP product at 10 flux sites in northern China, Inter. J. Remote Sens., 34, 587-599, 2013.

Wickham, H.: ggplot2: elegant graphics for data analysis, Springer New York, 2009.

Wu, Z.: Chinese-fir, China Forestry Publishing House., Beijing, 1984.

Yang, Y., Chen, G., and Huang, B.: Variation in the soil water and nutrients between different rotation stands of Chinese-fir, J. Nanjing For. Univ., 24, 25-28, 2000.

Yue, S., Pilon, P., and Cavadias, G.: Power of the Mann-Kendall and Spearman's rho tests for detecting monotonic trends in hydrological series, J. Hydrol., 259, 254-271, 2002.

Zhao, M. and Running, S.: Drought-induced reduction in global terrestrial net primary production from 2000 through 2009 , Science, 329, 940-943, 2010.

Zhao, M., Heinsch, F., Nemani, R., and Running, S.: Improvements of the MODIS terrestrial gross and net primary production global dataset, Remote Sens. Environ., 95, 164-176, 2005.

Zhao, M., Running, S., and Nemani, R.: Sensitivity of Moderate Resolution Imaging Spectroradiometer (MODIS) terrestrial primary production to the accuracy of meteorological reanalyses, J. Geophysical Res., 111, 2005-2012, 2006. 